\title{
Los Naufragios (1542) de Álvar Núñez Cabeza de Vaca: España y los albores de la legalidad internacional
}

\section{Álvar Núñez Cabeza de Vaca's Shipwrecks (1542): Spain and the Dawn of International Law}

\section{Carlos Conde Solares ${ }^{1}$ \\ University of Northumbria at Newcastle (Reino Unido)}

ORCID: https://orcid.org/0000-0003-0431-2119

Recibido: 14-05-2021

Aceptado: 21-05-2021

\section{Resumen}

En este artículo propongo una lectura de los Naufragios (1542) de Álvar Núñez Cabeza de Vaca que se ciña a los términos del debate moral y político imperante en la España en que el explorador jerezano redactó su historia. A la luz de la Relectio prior de Indis recenter inventis (1538) de Francisco de Vitoria, se comprueba cómo el bagaje espiritual e ideológico de Cabeza de Vaca no fue fruto exclusivo de su periplo americano, sino más bien de su familiaridad con las coordenadas éticas propias de la España oficial de su tiempo: la que puso los cimientos de una incipiente legalidad internacional.

Palabras-clave: Álvar Núñez Cabeza de Vaca, Francisco de Vitoria, ius gentium, imperio español.

\footnotetext{
Abstract

In this article I contextualise Álvar Núñez Cabeza de Vaca's Shipwrecks (1542) within the framework of the moral and political debates that were

${ }^{1}$ (carlos.solares@northumbria.ac.uk). Profesor de Historia de España en la Universidad de Northumbria (Reino Unido) y Coordinador de la asociación Foro de Profesores. Sus últimas publicaciones son La espiritualidad cristiana en la España del siglo XV: entre corte y monasterio, 'The Moral Dimensions of Sufism and the Iberian Mystical Canon'y El canon heterodoxo de la gran mistica hispánica: beatas, meditación e iluminismo.
} 
prevalent in Spain in the late 1530s, when the explorer redacted his chronicle. Cabeza de Vaca's ideas are not just a product of his extraordinary American experience. Shipwrecks also reflects official ethical policies of the Spanish Empire with which he was familiar. These were being shaped by authors such as Francisco de Vitoria, whose Relectio prior de Indis recenter inventis (1538) planted the early seeds of international law.

Keywords: Álvar Núñez Cabeza de Vaca, Francisco de Vitoria, ius gentium, Spanish Empire.

De entre los muchos testimonios de las primeras décadas del descubrimiento, muy pocos han suscitado un interés tan intenso y multidisciplinar como la "Relación que dió Álvar Núñez Cabeza de Vaca” de su calamitosa experiencia americana entre 1527 y 1537. Abundan las ediciones críticas de su "Relación", publicada en 1542, y frecuentemente acompañada de los "Comentarios" expiatorios sobre su también accidentado gobierno de la colonia del Río de la Plata entre 1540 y 1545, redactados estos últimos por su secretario Pedro Hernández 2 . La "Relación", más conocida bajo el novelesco título de Naufragios, cuenta con múltiples traducciones que ilustran el interés universal que sigue despertando la pionera peripecia norteamericana del explorador jerezano. Los Naufragios han servido además como inspiración de narrativas de ficción histórica, y han sido objeto de estudio y escrutinio desde las más diversas disciplinas.

A pesar de tan prolífica tradición académica, y sin menoscabo del valor historiográfico de la copiosa bibliografía generada, lo cierto es que gran parte de las interpretaciones de la vida y obra de Álvar Núñez Cabeza de Vaca (c.1488 - c.1560) parten de parámetros que le eran ajenos: así sucede con estudios generalmente valiosos, como los etnográficos y antropológicos, pero también con otros que, lastrados de presentismo negrolegendario, lo son menos. En este artículo propongo una lectura de los Naufragios que se ciña a las coordenadas del debate moral y político imperante en la España en que Álvar Núñez redactó su historia, en torno a los años comprendidos entre 1537 y 1540 . Dichas coordenadas eran las propias de un imperio católico que escribía las primeras líneas del derecho internacional. En concreto, me fijaré en la armonía entre los Naufragios y las lecciones y Justos Títulos auspiciados por Francisco de Vitoria (c. 1483-1546), y también dirigidos al emperador Carlos $\mathrm{V}$ entre diciembre de 1538 y enero de 1539. Los Naufragios pueden así leerse a la luz de la Relectio prior de Indis recenter inventis (1538) del escolástico.

${ }^{2}$ La más completa de estas ediciones y traducciones sigue siendo la de Rolena Adorno y Patrick Charles Pautz (1999). Presentada en tres volúmenes, contiene no solo la transcripción de la "Relación" (los Naufragios) de 1542, sino también su traducción al inglés y un estudio biográfico del propio Álvar Núñez que hace uso de abundantes materiales de archivo.

Araucaria. Revista Iberoamericana de Filosofia, Politica, Humanidades y Relaciones Internacionales, año $23, \mathrm{n}^{\circ} 47$. Segundo cuatrimestre de 2021. Pp. 91-109. ISSN 1575-6823 e-ISSN 2340-2199 https://dx.doi.org/10.12795/araucaria.2021.i47.05 
Como es bien sabido, los Naufragios presentan una crónica, relativamente breve, de los episodios que acaecieron principalmente al propio Álvar Núñez Cabeza de Vaca y a tres de sus acompañantes (Andrés Dorantes Carranza, Alonso del Castillo Maldonado, y el africano Estevanico) tras el estrepitoso infortunio de la expedición a la Florida liderada por Pánfilo de Narváez en 1527. Las desventuras suceden en la década que transcurre entre entonces y su regreso a España en 1537, momento en el que el explorador emprende la tarea de recomponer sus recuerdos para dar cuenta de sus vivencias ante el emperador. Una parte significativa de los estudios acerca de los Naufragios se centra en la comprobación (materialmente imposible) de los eventos que suceden entre 1527 y 1537, a través del análisis textual, la hipótesis, el cotejo de otros documentos relativos a la expedición y la especulación basada en preceptos psicológicos, teológicos, geográficos, antropológicos e incluso etnográficos ${ }^{3}$.

Aunque todo ello contribuye a revelar varias dimensiones interpretativas del texto y de su valor cultural, conviene también seguir pistas más fácilmente constatables a la hora de explicar la naturaleza de los Naufragios. Me refiero a las ideas preponderantes en España en el momento en el que Álvar Núñez escribe su crónica, a finales de la década de 1530. Este cambio de contexto cronológico en el foco de estudio (pasando del propio de los eventos narrados al del proceso de escritura) produce un importante cambio de perspectiva. En lo tocante a la conquista, los escolásticos de Salamanca estaban construyendo un paradigma de legitimidad cristiana que derivaría en una sofisticada legalidad internacional, parcialmente recogida en las Leyes Nuevas de Indias, cuya primera promulgación data precisamente de 1542. Sugiero, entonces, reflexionar sobre la intencionalidad del autor.

Álvar Núñez busca con su escrito hacerse merecedor de un nuevo destino político en el Nuevo Mundo. Para ello combina la narración de su epopeya personal con su conocimiento de las ideas sobre la expansión imperial que prevalecían en la corte de Carlos V a su regreso a España. En otras palabras, la reconstrucción de los eventos que suceden entre 1527 y 1537 solo puede entenderse a partir de una mirada retrospectiva impregnada de los valores dominantes en los años subsiguientes. Los Naufragios se convierten así en un manual práctico de lo que Vitoria llamaba en sus razonamientos una conquista "perfecta", sin "escándalo" ni exceso, ajustada a unos códigos morales que partían de la base innegociable de la dignidad del hombre indígena.

Porque muy distintos son los derechos de la guerra que se hace contra hombres perversos y agresores y los de la guerra contra inocentes e ignorantes. Como también ocurre en materia de escándalos, pues hay una manera de evitar el

${ }^{3}$ Alfredo Jiménez Núñez define el género de los Naufragios como “etnoliteratura” (Jiménez Núñez 2005: 109-21).

Araucaria. Revista Iberoamericana de Filosofía, Política, Humanidades y Relaciones Internacionales, año $23, \mathrm{n}^{\circ} 47$. Segundo cuatrimestre de 2021. Pp.91-109. ISSN 1575-6823 e-ISSN 2340-2199 https://dx.doi.org/10.12795/araucaria.2021.i47.05 
escándalo de los fariseos, y otra distinta para evitar el de los pusilánimes y enfermos.

Francisco de Vitoria, 1538. Relecciones sobre los indios y el derecho de guerra, p. 95 .

Los acontecimientos descritos por Álvar Núñez Cabeza de Vaca comienzan con la partida de la expedición de Pánfilo de Narváez desde España en 1527. Los problemas se suceden desde que, al llegar a Santo Domingo, se produce la deserción de parte de los hombres de Narváez, seducidos por las promesas de riqueza de los españoles ya establecidos en la isla. Poco después, un huracán provoca la pérdida de dos barcos. Los supervivientes, entre los que se encuentra el propio Álvar Núñez, llegan a Florida durante la Semana Santa de 1528. En ese momento, muy cuestionado ya su liderazgo, Pánfilo de Narváez decide dividir la expedición: 300 hombres se adentran en la península de Florida y un centenar permanece en la costa guardando los barcos restantes. No volverán nunca a reagruparse. A partir de entonces, la crónica de Álvar Núñez da noticia de cómo el contingente precariamente liderado por Narváez se va desintegrando con el paso de los años, víctima de enfermedades, ahogamientos y enfrentamientos tanto entre sí como con tribus indígenas. La desesperación lleva a algunos incluso a la antropofagia, que Álvar Núñez describe con la cotidianidad de lo extraordinario:

(...) y como las casas eran tan desabrigadas, comenzóse a morir la gente, y cinco cristianos que estaban en el rancho en la costa llegaron a tal extremo, que se comieron los unos a los otros, hasta que quedó uno solo, que por ser solo no hubo quien lo comiese.

Álvar Núñez Cabeza de Vaca, 1542. Naufragios, capítulo 14.

El meollo de los Naufragios se centra en la experiencia de Álvar Núñez, en compañía de Dorantes, Castillo y Estevanico, durante su extraordinario periplo por los territorios del actual suroeste de los Estados Unidos y hasta alcanzar la costa del Pacífico. Allí, el jerezano se reúne con la expedición de Diego de Alcaraz para regresar finalmente a España en 1537. Entre tanto, los Naufragios describen las relaciones que establecen los protagonistas con diversas tribus amerindias, y que van desde un discutido régimen de cautiverio o semiesclavitud hasta el desempeño de curiosos papeles que favorecían su supervivencia e itinerancia como mensajeros, comerciantes y chamanes.

Algunos de los trabajos más reveladores dedicados a la obra de Álvar Núñez se ocupan del cotejo de los Naufragios con otros testimonios paralelos. En este sentido, las investigaciones archivísticas de Robert Goodwin son de particular interés (Goodwin 2007: 147-173) . La más importante de las fuentes

${ }^{4}$ Goodwin se hace eco de diecisiete documentos sobre la expedición a Florida, pertenecientes al 
alternativas sobre la epopeya del explorador jerezano es, claro está, la Historia general y natural de las Indias del cronista y naturalista Gonzalo Fernández de Oviedo (1478-1557). Fernández de Oviedo incluyó en su crónica, escrita en los primeros años de la década de 1540, seis capítulos acerca de la excursión de Álvar Núñez y sus acompañantes. Se basó para ello en la tradición textual de la llamada Carta de Santo Domingo (hoy perdida), un documento conjunto de los tres supervivientes españoles al que Oviedo accede en 1539, antes de emprender viaje de regreso a España, y antes de añadir un séptimo capítulo tras conocer a Álvar Núñez y consultar la primera edición de los Naufragios $^{5}$. El objeto de estos cotejos archivísticos y textuales suele ser la reconstrucción de la ruta seguida por los náufragos, la especulación en torno a los episodios más llamativos que describe Álvar Núñez, y el establecimiento de una tradición textual que sirva para interpretar la naturaleza de los hechos protagonizados por los cuatro supervivientes, en especial de aquellos de apariencia milagrosa ${ }^{6}$.

Las discrepancias, en énfasis y contenidos, entre la selección de pasajes de Fernández de Oviedo y la de Álvar Núñez Cabeza de Vaca sirven para ilustrar que es mucho más prolífico fijarse en las expectativas (políticas, teológicas, morales) del receptor de los Naufragios que especular acerca de la fidelidad a unos hechos cuya comprobación es fútil. Fernández de Oviedo, con su prurito de objetividad, excluye de su crónica todos los episodios milagrosos, cualidad que solo adjudica a la propia supervivencia de los cuatro náufragos. Muestra además su escepticismo cuando insinúa el efecto placebo de las supuestas curaciones de indios ciegos o tuertos, comentando que "si los cristianos no los sanaban a todos, los indios creían que los podían sanar"7. Goodwin considera, con buen criterio, que el foco de Cabeza de Vaca en estos pasajes se debe a su creencia de que los episodios milagrosos que se atribuye serían bien recibidos en España (Goodwin 2007: 168). En la realidad cotidiana del Nuevo Mundo, sin embargo, y sin la misma motivación que el jerezano, Oviedo prefiere censurar, o al menos omitir, episodios cuya relación sin duda conocía, pero que podrían comprometer la credibilidad de su obra cronística ${ }^{8}$. En ambos casos, la clave

Archivo General de Indias de Sevilla. Los legajos incluyen cinco "declaraciones", "informaciones y probanzas de servicios y méritos" escritos por supervivientes de la expedición (Goodwin 2007: 147148). Estas hojas de servicios, currículos o cartas de presentación eran importantes para sus autores desde un punto de visto legal y laboral, como luego se verá.

5 Oviedo, Historia general y natural de las Indias, IV, 287-318 [p. 314]. Véase Goodwin (2007: 147-173) para una útil comparativa de ambos textos.

${ }^{6}$ Los documentos hallados por Goodwin en el Archivo de Indias rara vez se detienen en los episodios "milagrosos" o semi-mágicos de la expedición, como el de la combustión espontánea de la maleza, la curación repentina de un indio muerto, el temor de los indios por el demonio Mala Cosa, la exitosa operación a corazón abierto que Álvar Núñez practica a un indio, el episodio de la Mora de Hornachos, o el brote epidemiológico causado por la ira de los españoles (véase Goodwin 2007: 149-156).

${ }^{7}$ Fernández de Oviedo, Historia general y natural de las Indias, IV, 306b.

${ }^{8}$ Por otra parte, una de las principales preocupaciones de la iglesia en el Nuevo Mundo era precisamente un sincretismo religioso como el que se puede vislumbrar en prácticas que, como

Araucaria. Revista Iberoamericana de Filosofia, Política, Humanidades y Relaciones Internacionales, año 23 , no 47. Segundo cuatrimestre de 2021. Pp. 91-109. ISSN 1575-6823 e-ISSN 2340-2199 https://dx.doi.org/10.12795/araucaria.2021.i47.05 
está en las expectativas de Oviedo y Cabeza de Vaca acerca de lo que creen que les conviene que el destinatario lea en sus escritos. También cabe recordar que la crónica de Oviedo se basa en el documento conjunto de Santo Domingo de 1539, seguramente enviado por Dorantes ya de camino a España (Goodwin 2015: 179-206).

En todo caso, la peculiar evolución de las relaciones entre Álvar Núñez y los diversos pueblos indígenas que encuentra a su paso ha centrado, históricamente, la atención de los lectores de los Naufragios, así como de una mayoría de estudiosos. Esto ha llevado, en no pocas ocasiones, a una percepción extemporánea y anacrónica del texto y de su protagonista ${ }^{9}$. Como sucede con la obra de Fray Bartolomé de las Casas, los escritos de Álvar Núñez (tanto los Naufragios como los Comentarios) se prestan a una narrativa superficial, sentimental y maniquea, en parte fomentada por el propio autor, que presenta al jerezano como oasis de excepcional humanidad que contrasta, grosso modo, con la avaricia, el egoísmo y la violencia inherentes al proceso colonial ${ }^{10}$. Como bien resume Ralph Bauer, la expansión de los Estados Unidos durante el siglo XIX a costa de territorios que habían formado parte de la corona española supuso el comienzo de una batalla por la identidad nacional mediante la cual la historiografía protestante se apropió de personajes como Las Casas o Cabeza de Vaca a la hora de construir su propia genealogía (Bauer 2004: 487).

Este discurso decimonónico manipulará las crónicas españolas del Nuevo Mundo siguiendo el método establecido por los primeros hispanistas norteamericanos, como Washington Irving, George Ticknor y William Hickling Prescott: el de la definición de la identidad norteamericana como negación antitética de unos atributos pintorescos y medievalistas gratuitamente adjudicados a España. De esta manera, textos tan significativos para la historia de las civilizaciones, desde un punto de vista legal y político, se ven relegados al papel de coartadas negrolegendarias ${ }^{11}$. A los propios Colón, Las Casas o Cabeza de Vaca se les desviste de su españolidad para convertirles en precursores de la americanidad, a través de la intervención sentimental propia del romanticismo. Esta tendencia permanece en las muchas aproximaciones superficiales a los Naufragios que se siguen haciendo. Por ejemplo, Ali Zaidi celebra la supuesta

las de Álvar Núñez, combinaban el chamanismo indígena con los rituales cristianos. Los archivos inquisitoriales de Fray Juan de Zumárraga, primer arzobispo e inquisidor de México desde 1536, refuerzan esta hipótesis de Goodwin (2007: 170-173).

${ }^{9}$ Florencia Defelippe observa que la relación de Álvar Núñez con las poblaciones americanas (en los Comentarios) es de "vasallaje", ya que "persiste y enfatiza en todo momento su objetivo evangelizador" (Defelippe 2017: 51).

${ }^{10}$ El meticuloso estudio biográfico de Robin Varnum tiende a presentar a Álvar Núñez, con indisimulada simpatía, como gran defensor de los indígenas de ambas Américas (Varnum 2014).

${ }^{11}$ Esta interpretación negrolegendaria de la historia temprana del imperio español ha sido rigurosamente contestada desde diversos enfoques académicos en la última década. Véanse en particular las obras de John Elliott (2006 \& 2012), Stanley Payne (2011), María Elvira Roca Barea (2016) y María José Villaverde Rico y Francisco Castilla Urbano (eds., 2016). 
"transformación espiritual" de Álvar Núñez, propiciada por "la alquimia del sufrimiento", que le otorgaría una "nueva identidad americana" (Zaidi 2014: 109-117) ${ }^{12}$. Sin justificación racional, este tipo de lugar común confiere cualquier aspecto virtuoso a un componente "americano" que se destila por oposición con lo español.

Sin embargo, y a pesar de la habitual deriva simplista de la aproximación emotiva al texto, sus dimensiones empática, afectiva y sentimental siguen siendo parte importante de su esencia. El "giro afectivo" en los estudios hispanoamericanos que propone Jerónimo Arellano a partir, precisamente, de los Naufragios, sirve para explorar los vínculos de comunicación establecidos, desde un principio, entre europeos e indígenas (Arellano 2018: 548-560). La exteriorización y expresión, a veces simbólica, mitológica o religiosa, de emociones universales como el miedo es, de hecho, una de las herramientas interpretativas más poderosas a la hora de descifrar pasajes como los recordados por Álvar Núñez y omitidos por Oviedo: la "Mala Cosa" que causa enfermedad en los indígenas tras establecer contacto con españoles, las actividades de la Mora de Hornachos, las curaciones milagrosas o las aparentes intervenciones providenciales, como la del matorral en llamas, que salva al protagonista del frío.

Estos pasajes son los más llamativos para quienes debaten la validez de los Naufragios como fuente histórica. También lo son para los estudiosos que defienden la vigencia del texto en los cimientos del canon literario hispanoamericano. Caben diferentes hipótesis sobre la significación que Cabeza de Vaca quiso dar a los episodios de proto-realismo mágico. Por ejemplo, Carlos Jáuregui niega la insinuación del náufrago de que la Mala Cosa sea la antítesis mítica de su benevolencia cristiana: defiende que se trata de una formulación del miedo que su presencia infunde en los indígenas (Jáuregui 2014: 421-427). Como bien señala Rolena Adorno, la "negociación del miedo" se convierte frecuentemente en el primer intercambio emocional entre españoles e indígenas: ambos lo emplean, de manera semiconsciente, dependiendo de su posición de poder con respecto al otro (Adorno 1991: 167) . $^{13}$.

El malentendido de actos rituales, presentados por definición a partir del filtro propio de cada cultura, es una consecuencia frecuente de estos intercambios $^{14}$. Esto sucede con el lenguaje corporal aparentemente emotivo,

${ }^{12}$ Así funciona, por ejemplo, el monográfico de David Howard Conquistador in Chains: Cabeza de Vaca and the Indians of the Americas: se trata de un libro de esencia negrolegendaria que presenta a Alvar Núñez como conquistador iluminado que contrasta con la perversión propia del resto (Howard 1996).

13 Carmen Godoy reflexiona sobre alteridad e identidad en los Naufragios como construcción etnográfica del conocimiento del Otro (Godoy 2010: 1-18).

14 Pienso, como ejemplo más conocido, en la manida interpretación literal de la investidura de Hernán Cortés con las plumas de Quetzalcoatl a su llegada a Tenochtitlán. Un acto ritual, diplomático, se percibe como sumisión e incluso idolatría contra el peso de toda la evidencia disponible, que hace

Araucaria. Revista Iberoamericana de Filosofia, Política, Humanidades y Relaciones Internacionales, año $23, \mathrm{n}^{\circ} 47$. Segundo cuatrimestre de 2021. Pp.91-109. ISSN 1575-6823 e-ISSN 2340-2199 https://dx.doi.org/10.12795/araucaria.2021.i47.05 
también sujeto a malinterpretación ritual, y más en un contexto de difícil descodificación lingüística que convierte lo gestual en elemento primordial del proceso comunicativo ${ }^{15}$. Por ejemplo, Álvar Núñez se maravilla de la empatía de los habitantes de uno de los pueblos amerindios cuando, al verles llegar en un estado lamentable, "comenzaron todos a llorar recio" (Naufragios, capítulo 12). Sin embargo, en un pasaje posterior que ilustra su aprendizaje de usos culturales y antropológicos, observa cómo unos indígenas

(...) tienen por costumbre, quando se conosçen y de tiempo a tiempo se veen, primero que se hablen estar media hora llorando, y acabado esto, aquel que es visitado se levanta primero y da al otro todo quanto possee, y el otro lo rescibe ${ }^{16}$. Álvar Núñez Cabeza de Vaca, 1542. Naufragios, capítulo 15.

Estas lecturas de los Naufragios son particularmente relevantes a la hora de explorar los mecanismos de entendimiento e hibridación implícitos en los procesos de comunicación y evangelización. Para apreciar su capital importancia en el contexto de los Naufragios, conviene recordar los parámetros legales auspiciados por los Justos Títulos y por el De Indis de Francisco de Vitoria, producidos en coincidencia cronológica con la crónica de Álvar Núñez: la legitimidad del mismo proceso colonizador pende del hilo de una comunicación religiosa efectiva, de un proceso de conversión que requería una conexión espiritual profunda entre españoles e indios. En este sentido, los episodios de curanderismo de Álvar Núñez suponen un hito en la integración entre ritos europeos (cristianos, pero también moriscos) y amerindios ${ }^{17}$. La superposición de oraciones y rituales cristianos, como el Padrenuestro o la señal de la cruz, en ceremonias y curas precolombinas es propia de una cultura de conversión, la española, que contaba con una larga tradición de diálogo interreligioso en el contexto de las tres culturas.

La aproximación etnográfica a estos episodios suele resultar en interpretaciones experienciales e individualistas de los mismos, incidiendo en la supuesta excepcionalidad de Álvar Núñez entre los exploradores y conquistadores españoles. Así, Phiana Borunda establece el alejamiento de Álvar Núñez de la representación caricaturizada del conquistador, destacando su propia transformación espiritual como supuesto contrapunto pacífico a la práctica expeditiva habitual en todo proceso imperial de la temprana (y tardía)

insostenible la creencia de que los aztecas consideraran dioses a los españoles.

${ }^{15}$ Bonvillian, Ingram y McCleary estudian las referencias al lenguaje gestual en los Naufragios (Bonvillian, Ingram, McCleary 2009: 132-165).

${ }^{16}$ En un contexto diferente, Janet Whatley menciona los hábitos rituales de los Tupinamba de Brasil, que tenían también por costumbre diplomática el saludo con lágrimas (Whatley 1990: xxxiv).

17 Phiana Borunda define el curanderismo de los Naufragios como un ejemplo de etnografía transnacional (Borunda 2016: 92). 
modernidad $^{18}$. El matiz, importante, que cabe añadir es que los Naufragios reflejan exactamente el ethos imperial predominante en el momento y lugar de redacción de la crónica, cuyos parámetros definía, entre otros, Vitoria:

Contra esto diremos que ellos estaban pública y privadamente en pacífica posesión de sus cosas, y, por lo tanto, mientras no se demuestre lo contrario, deben ser tenidos por verdaderos señores y no puede despojárseles de su posesión, sin causa justa (...). Es manifiesto que tienen cierto orden en sus cosas, puesto que tienen ciudades debidamente regidas, matrimonios reglamentados, magistrados, señores, leyes, artesanos, mercados, todo lo cual requiere uso de razón. Tienen también una especie de religión, y no yerran tampoco en las cosas que para los demás son evidentes. Dios y la naturaleza no les faltan en lo que es necesario para la mayor parte de la especie.

Francisco de Vitoria, 1538. Relecciones sobre los indios y el derecho de guerra, pp. $39-40 \& 50$.

El propio Álvar Núñez traza en su crónica un autorretrato que le distinga como buen cristiano. Para ello se hace eco de la supuesta incredulidad de los indígenas al ser informados de que venía del mismo lugar que el resto de los españoles con los que habían establecido contacto:

Ellos no querían sino ir con nosotros hasta dejarnos, como acostumbraban, con otros indios; porque si se volviesen sin hacer esto, temían que se morirían; que para ir con nosotros no temían a los cristianos ni a sus lanzas. A los cristianos les pesaba de esto, y hacían que su lengua les dijese que nosotros éramos de ellos mismos, y nos habíamos perdido mucho tiempo había, y que éramos gente de poca suerte y valor, y que ellos eran los señores de aquella tierra, a quien habían de obedecer y servir. Mas todo esto los indios tenían en muy poco o nada de lo que les decían; antes, unos con otros entre sí platicaban, diciendo que los cristianos mentían, porque nosotros veníamos de donde salía el sol, y ellos donde se pone; y que nosotros sanábamos los enfermos y ellos mataban los que estaban sanos; y que nosotros veníamos desnudos y descalzos, y ellos vestidos y en caballos y con lanzas; y que nosotros no teníamos codicia de ninguna cosa, antes todo cuanto nos daban tornábamos luego a dar, y con nada nos quedábamos, y los otros no tenían otro fin sino robar todo cuanto hallaban, y nunca daban nada a nadie. Y de esta manera relataban todas nuestras cosas y las encarecían, por el contrario, de los otros; (...) Finalmente, nunca pudo acabar con los indios creer que éramos de los otros cristianos...

Álvar Núñez Cabeza de Vaca, 1542. Naufragios, capítulo 34.

Álvar Núñez se presenta a sí mismo como perteneciente a una tercera categoría, la de un intermediario con los indígenas. Tal autorretrato responde sin duda a su ambición política: la de liderar una nueva expedición con las credenciales propias de quien es capaz de protagonizar una conquista "limpia",

18 Véase Borunda 2016: 92.

Araucaria. Revista Iberoamericana de Filosofia, Política, Humanidades y Relaciones Internacionales, año $23, \mathrm{n}^{\circ} 47$. Segundo cuatrimestre de 2021. Pp. 91-109. ISSN 1575-6823 e-ISSN 2340-2199 https://dx.doi.org/10.12795/araucaria.2021.i47.05 
"perfecta", "sin escándalo", conforme a las preferencias del Imperio español. Sin tener en cuenta la intencionalidad del autor y la agenda del destinatario, es tentador explicar que el propio Álvar Núñez experimenta un proceso de aculturación como consecuencia de su larga travesía ${ }^{19}$. Tales interpretaciones vendrían a reforzar la narrativa negrolegendaria que despoja a Álvar Núñez, como a Las Casas, de su españolidad, e incluso de su cristianismo, proponiendo en su lugar el establecimiento de una nueva identidad, la criolla.

Este proceso de supuesta aculturación de Álvar Núñez alcanza incluso a su lengua materna, el castellano. La negación de su españolidad es habitual en la crítica literaria. Enrique Pupo-Walker se pregunta "en qué lengua ocurrió mucho de lo que se nos describe", y considera "razonable suponer que el impacto de vivencias lingüísticas tan extremas pudo haber afectado la capacidad de expresión que Núñez desplegaría al retomar el castellano, después de haber vivido casi ocho años en las penumbras culturales del paleolítico americano" (Pupo-Walker 1990: 165). Los Naufragios, leídos como libro de viaje iniciático, formarían así parte de una tradición narrativa colonial en la que el explorador se descubre a sí mismo en su interactuación tanto con otros españoles como con los pueblos indígenas, resultando en un abandono de su identidad original ${ }^{20}$. Sin embargo, conviene alzar la mirada al momento de la redacción: ya meses, quizás años después de su regreso a España y con el objetivo de hacerse acreedor de una misión política y de liderazgo en el Nuevo Mundo, acaso en la propia Florida. Es decir, el contexto que mejor explica la escritura de los Naufragios es el español antes que el americano.

Bajo este prisma, la habilidad narrativa, y política, de Cabeza de Vaca queda patente: sus actitudes coinciden con las deseables según la incipiente nueva legalidad. Además de por su buen trato con los indígenas, Álvar Núñez también reserva un papel destacado para Estevanico, quien en varias ocasiones actúa no solo como intermediario entre Cabeza de Vaca, Dorantes y Castillo y los indígenas, sino que también es protagonista, con cierta agencia e independencia, de los mismos "milagros" y curaciones que aquellos ${ }^{21}$. La consideración no es anecdótica en el contexto de un imperio que reflejaría en

19 Véanse Rabin (1999: 40-45) y Todorov (1982). Además, Marešová se fija en el discurso desmitificador según el cual Álvar Núñez deja varias veces sin explicar fenómenos que resultaban ajenos a la cultura cristiana, y que podrían ser síntoma de su propia aculturación (Marešová 2016: 33-41).

20 Hachim y Hurtado ubican los Naufragios al comienzo de una tradición conjunta con los Infortunios De Alonso Ramírez (1690) de Carlos de Sigüenza y Góngora. Ambos textos se interpretan bajo el prisma de la narrativa colonial como síntesis de lo histórico y lo ficticio que parte de la subjetividad criolla (Hachim y Hurtado 2018: 172-188). Alex Krieger estudia los Naufragios como libro de viajes en We Came Naked and Barefoot: The Journey of Cabeza de Vaca across North America (Krieger 2002). Se trata de una línea semejante a la seguida por Wild (1991), Udall (1995) y Schneider (2007).

${ }^{21}$ Elvira Morell estudia en los Naufragios los pasajes que sitúan a Estevanico "en el centro de los milagros y de la propia organización del grupo para su supervivencia” (véase Morell 2018: 399-413).

Araucaria. Revista Iberoamericana de Filosofia, Política, Humanidades y Relaciones Internacionales, año 23 , $\mathrm{n}^{\circ} 47$. Segundo cuatrimestre de 2021. Pp. 91-109. ISSN 1575-6823 e-ISSN 2340-2199 https://dx.doi.org/10.12795/araucaria.2021.i47.05 
sus inminentes leyes la abolición tanto de la esclavitud como de la encomienda feudalista. Más allá de consideraciones como la relativa falta de "refinamiento expositivo" de Álvar Núñez en comparación con autores con mayor voluntad de estilo, como López de Gómara, Antonio de Guevara o el Inca Garcilaso, los Naufragios son ante todo un texto legal frecuentemente juzgado bajo parámetros ajenos a las prioridades del autor, como los literarios ${ }^{22}$. Para Cabeza de Vaca, en el momento de la redacción de su texto, importa mucho más la capacidad de transmitir su inequívoca alineación con las políticas imperiales en torno a la conquista, en temas tan sensibles como el trato con indígenas y africanos, que reflejar en su crónica su propia destreza literaria.

El papel del africano en los Naufragios permite a Álvar Núñez profundizar en la plasmación de los valores que quiere transmitir al Emperador Carlos V. Cassander Smith analiza cómo Álvar Núñez utiliza la figura de Estevanico para ejercer de enlace entre identidades diferentes: la suya (y, por extensión, de Dorantes y Castillo) y la de los indios americanos ${ }^{23}$. El papel de Estevanico contrasta vivamente con el desempeñado por otros africanos en textos del temprano colonialismo: lo habitual es que la presencia del hombre negro en estas crónicas se limite a lo anecdótico y circunstancial (véase Smith 2012: 167). Sin embargo, en los Naufragios abundan las referencias a las acciones, igualmente valerosas e ingeniosas, del africano: no solo acomete las mismas labores que los españoles, incluida la curación por ritual híbrido cristiano, morisco y chamánico, sino que destaca además por sus dotes comunicativas y lingüísticas, que le permiten ejercer de enlace, con identidad y categoría propias, entre los otros dos grupos (españoles e indígenas). En esta armónica relación de Cabeza de Vaca es fácil vislumbrar los ideales utópicos que abundaban en los textos y consejos en boga en la corte de Carlos $\mathrm{V}$ durante el proceso de redacción de los Naufragios.

(...) Que no es lícito despojar de sus cosas a sarracenos ni a judíos ni a cualesquier otros infieles, nada más que por el hecho de ser infieles, y el hacerlo es hurto o rapiña, lo mismo que si se hiciera a los cristianos (...). Por lo tanto, no hay nadie que por derecho natural tenga el dominio del orbe.

Francisco de Vitoria, 1538. Relecciones sobre los indios y el derecho de guerra, pp. $44 \& 56$.

Debido precisamente a la porosidad entre los diferentes colectivos en la crónica de Álvar Núñez, el texto ha seguido inspirando la empatía de las

\footnotetext{
${ }^{22}$ Enrique Pupo-Walker observa que Álvar Núñez emprende, como tantos cronistas de Indias, "la acción primigenia de nombrar lo desconocido", como "precursora acción nominalista (...) que puede aproximar la Relación (...) tanto a las entelequias primarias del mito como a poderosas fabulaciones que en nuestra tradición cultural estarían idealmente representadas por Cien años de soledad" (PupoWalker 1990: 195).

${ }^{23}$ Véase Smith (2012: 167-191).
}

Araucaria. Revista Iberoamericana de Filosofia, Política, Humanidades y Relaciones Internacionales, año $23, \mathrm{n}^{\circ} 47$. Segundo cuatrimestre de 2021. Pp. 91-109. ISSN 1575-6823 e-ISSN 2340-2199 https://dx.doi.org/10.12795/araucaria.2021.i47.05 
identidades en conflicto en el continente americano a lo largo de la historia, con ramificaciones contemporáneas. La esencia universal de los Naufragios, con sus elementos de dislocación, alienación de los grupos establecidos (hispanohablantes e indígenas) y, en general, la "otredad" que permea el texto han sido reivindicadas como representaciones precursoras de, por ejemplo, la literatura chicana ${ }^{24}$. Desde las semillas de realismo mágico que se pueden hallar en el texto de Álvar Núñez hasta los paisajes del suroeste americano descritos, por primera vez, por un hablante de español, no es difícil vislumbrar los mecanismos que siguen tentándonos a adoptar, de manera anacrónica, a Álvar Núñez Cabeza de Vaca como un precursor, adelantado no solo en título sino en el tiempo.

Conviene resistir, o al menos modular, esa tendencia para regresar la mirada al Álvar Núñez que fue, en el momento de la redacción de los Naufragios, un español de su tiempo escribiendo un texto que reflejaba su familiaridad con los debates éticos, teológicos, políticos y legales del temprano imperio, y que iría sin duda adaptando a las expectativas de su audiencia, poniendo el énfasis en aquellos aspectos de su conveniencia. Robert Goodwin reconstruye el proceso de redacción recordando certezas que es fácil perder de vista al sumergirse en los Naufragios: ni Álvar Núñez ni sus acompañantes tenían los medios (tampoco la vocación) para documentar su experiencia en forma de diario, por lo que su relación es necesariamente un ejercicio de memoria; la primera vez que tuvieron la ocasión de contar su historia a otros españoles habían transcurrido ya ocho años desde su desembarco en Florida; el acto de recordar y resumir su experiencia comenzó con su encuentro con la expedición de Diego de Alcaraz, continuó con el gobernador de Culiacán y tuvo su tercera entrega oral en continente americano con su reunión con el virrey en la ciudad de México (Goodwin 2015: 179-190).

Es decir, como sucede con la mayoría de las crónicas no oficiales de la conquista, el proceso de recordar los eventos acaecidos se convierte, desde un principio, en una actividad administrativa, de justificación moral pero sobre todo legal, con consecuencias evidentes para unos exploradores que van reelaborando su historia para audiencias de cada vez mayor rango hasta culminar en la redacción de los Naufragios, cuyo destinatario es el hombre más poderoso del planeta, el emperador Carlos V. Como señala Goodwin, el emperador es mucho más que el real destinatario de la Relación de Álvar Núñez Cabeza de Vaca: Carlos V es, en cierto modo, también co-autor de la narración, en cuanto a que esta respondería a las preguntas e intereses del imperio en torno a las vicisitudes del terreno y de los pueblos indígenas en unos meses en los que se preparaba ya la expedición de Hernando de Soto a la Florida (Goodwin 2008: 1-12).

\footnotetext{
${ }^{24}$ Véase Gómez-Galisteo (2013: 147-166).
} 
En la entrevista que el emperador concedió a Álvar Núñez Cabeza de Vaca a su regreso a España, Carlos V ya conocía la "tradición oral" de la gesta de los náufragos ${ }^{25}$. También estaba convencido de la conveniencia de adoptar un ethos imperial inspirado en la filosofía de los escolásticos de Salamanca, de los Justos Títulos y el De Indis de Francisco de Vitoria, e incluso de las formulaciones utópicas de Bartolomé de las Casas, como reflejarían las Leyes Nuevas de Indias promulgadas apenas unos meses después de su encuentro con el jerezano. Por parte de Cabeza de Vaca, sus intenciones serían claras: obtener el beneplácito real para liderar una nueva expedición a la Florida, con su experiencia del territorio y de sus gentes como bagaje, pero también con su conocimiento de los parámetros políticos y morales que le podrían beneficiar en su ambición, con las Ordenanzas de 1526 como base.

Cabe especular acerca de los motivos de su relativo fracaso: Álvar Núñez no regresaría nunca a Florida, la expedición sería liderada en su lugar por Hernando de Soto, y Álvar Núñez sería recompensado con el gobierno de la provincia del Río de la Plata, a donde partiría en 1541 nada más concluir la redacción de sus Naufragios y tras rechazar la oferta de unirse a la expedición de Soto como su subordinado. Como bien recuerda Rolena Adorno a propósito de fuentes como la que nos ocupa, estos documentos no son históricos, sino retóricos, polémicos y escritos con la intención de influenciar decisiones políticas $^{26}$. Álvar Núñez solo cumplió en parte con su ambición. La propia Rolena Adorno se había fijado en los posibles motivos del éxito parcial del jerezano: las contradicciones de su Relación, no solo con respecto a lo detallado por un cronista oficial como Oviedo, sino también internas, en su propio texto: por ejemplo, en los Naufragios abundan tanto las referencias al empobrecimiento del territorio como las proclamaciones triunfalistas en torno a su supuesta riqueza natural (Adorno 1991).

La siguiente vuelta de tuerca a esta instrumentalización de una experiencia idealizada la daría Bartolomé de las Casas al poner los Naufragios como ejemplo de la predisposición pacífica de los amerindios a recibir el cristianismo (Adorno 2007) ${ }^{27}$. Con todo ello, no sería de extrañar que el emperador dudara de la idoneidad de Álvar Núñez para regresar como gobernador a un territorio del que ofrecía una visión inconsistente. Goodwin ofrece además otro motivo de

\footnotetext{
${ }^{25}$ Este conocimiento era, sin embargo, insuficiente para pertrechar la inminente expedición de Hernando de Soto. Goodwin encuentra la Real Cédula emitida por la Corona en 1537 en la que se ordena a la Casa de Contratación real que extraiga testimonio escrito a Álvar Núñez Cabeza de Vaca de todo lo acontecido en su periplo americano (Goodwin 2008: 9-12; Archivo General de las Indias, Ind. 1962, L5, fols. 273v-276v, de 26-10-1537).

${ }^{26}$ Rolena Adorno, Polemics of Possession (2007: 22).

${ }^{27}$ Claret Vargas destaca el poder de pacificación como la principal cualidad de la que Álvar Núñez hace gala en su escrito ante el emperador: se trata de la virtud distintiva de su liderazgo, con la que pretende diferenciarse de otros exploradores y conquistadores. Cabeza de Vaca se presenta como facilitador necesario de una conquista exitosa, sin derramamiento de sangre (Vargas 2007: 18).
} 
peso para que Carlos V dudara de la verdadera habilidad de Cabeza de Vaca, al menos como etnógrafo: más allá de la lectura tentativa de gestos rituales como las lágrimas, existe una clara contradicción entre la interpretación que hace Oviedo de los intercambios rituales entre tribus más allá del Río Grande (los Avavares) y la que parece defender Álvar Núñez. Mientras el explorador utiliza un lenguaje emotivo, calificándolas de "robos", el naturalista e historiógrafo se inclina por ofrecer una visión más atenuada de lo que está teniendo lugar: se trataba de desposesiones rituales, hipótesis esta que además se congracia con la observación del propio Cabeza de Vaca de que las tribus supuestamente robadas parecían "holgarse" de tal afrenta (véase Goodwin 2002: 179-206). El conocimiento y la correcta interpretación de estos usos no era baladí: al contrario, se trataba de aspectos clave a la hora de poner en práctica las tácticas de evangelización y expansión imperial recomendadas por los escolásticos, por Vitoria y por Las Casas.

El éxito de tales prácticas ofrecía como principal dividendo y deseable consecuencia la legitimidad ética de la expansión imperial. Conocida la función legitimadora de la evangelización en el proceso de conquista, no son de extrañar las alusiones bíblicas en la narrativa de Álvar Núñez. Algunas son meramente formulaicas, y la mayoría, superficiales: no merece la pena detenerse en la evidente recreación de aspectos somáticos de la Pasión de Cristo. El náufrago describe con estoicismo las llagas que sufre por su exposición al clima, a la geografía y a las vicisitudes en su periplo inicial por las costas del golfo de Florida y del sur de Texas. No omite tampoco ocasión que le sea propicia para blasonar de favor divino, por ejemplo, en sus designios y curaciones. El contexto es fecundo para ello, habida cuenta de que Álvar Núñez es el oficial de más alto rango que sobrevive a una desastrosa misión que en su inicio incluyó a varios centenares de cristianos. Desde los episodios proféticos (Mora de Hornachos) hasta los acontecimientos milagrosos con tonos bíblicos (el matorral en llamas) Álvar Núñez se presenta, aunque con la prudencia que impone el destinatario, como un explorador ungido por elección divina.

Menos evidentes, pero acaso más significativas, son las tipologías paulinas que identifica Kun Jong Lee en los Naufragios: el proceso de transformación e iluminación espiritual de Cabeza de Vaca puede entenderse como el de un tardío apóstol San Pablo, profeta español entre los indios americanos (Jong Lee 1999: 242). La transformación de los confines del imperio español en territorio bíblico es un fenómeno típico de la temprana narrativa colonial. A su regreso a España, armado de sus recuerdos y experiencias, Álvar Núñez se reinventa investido de renovada legitimidad. Para interpretar correctamente su texto, conviene tener en mente los parámetros agustinianos de De doctrina christiana en lo referido a la interpretación de signos, tanto literales como figurativos ${ }^{28}$. Estos

${ }^{28}$ Para indagar en esta idea de Steven Liparulo, véase Liparulo (2006: 1-25). 
intercambios transformadores, gestuales, espirituales, rituales pero también materiales forman parte de una misma estrategia imperial, la formulada por los escolásticos de Salamanca, que armoniza moralidad cristiana y mercantilismo.

Basándose en el principio de que los pueblos que comercian e interactúan en torno a una serie de normas civilizadoras se inclinarán antes a la convivencia fraternal que a la guerra, Álvar Núñez refleja el cambio cultural en el concepto de conquista que España protagoniza en el siglo XVI, y que desplaza el eje de expansión imperial desde la guerra hasta la pacificación ${ }^{29}$. Todo ello está vinculado, en los trabajos de los escolásticos salmantinos, con el incipiente estudio de la ciencia económica a partir de la teología: aunque Álvar Núñez no participa, evidentemente, del pensamiento estratégico de Luis Saravia de la Calle o Domingo de Soto, su posición como tesorero y colector de la expedición de Pánfilo de Narváez le supondría cierta familiaridad con los rudimentos del funcionamiento financiero de las colonias españolas. Así, Nan Goodman destaca cómo Álvar Núñez demuestra intuición económica a la hora de desempeñar con éxito su labor como comerciante entre las distintas tribus indígenas (Goodman 2005: 242) ${ }^{30}$. El gobierno de Río de Plata le daría después la oportunidad de poner en práctica, aunque con desigual éxito sobre el terreno, unas políticas con cuyo proceso de formulación estaba sin duda familiarizado.

$\mathrm{Su}$ propia peripecia norteamericana le vino además a demostrar que las diferencias entre europeos e indios, categorías hasta entonces exclusivamente naturales, estaban supeditadas al estatus económico y eran susceptibles de cambiar, como su propia biografía ilustraba de manera palmaria. En este sentido, Goodman reflexiona sobre cómo tanto el incipiente mercantilismo como la experiencia vivida de Álvar Núñez Cabeza de Vaca venían a refutar, de manera ya irreversible en el ámbito de la hispanidad, el argumento de raíz aristotélica que identificaba a los amerindios con "hombres naturales" (Goodman 2005: 237-238). A partir de este momento, cualquier ser humano en posición de subyugación económica podría convertirse en "indio", y esto incluía a los propios españoles. Tal epifanía resultaría, de paso, en la elevación del hombre indígena por encima de aquella categoría aristotélica a medio camino entre el hombre racional y el animal, y su consolidación como ciudadano titular de dignidad.

Que antes de la llegada de los españoles, los indios eran verdaderos dueños, tanto pública como privadamente.

Francisco de Vitoria, 1538. Relecciones sobre los indios y el derecho de guerra, p. 52 .

${ }^{29}$ Véanse los estudios de Rabasa (1995: 175-185), Bauer (2004: 487-495) y Goodman (2005: 229250) sobre este cambio de paradigma.

${ }^{30}$ Nancy Hickerson explica la supervivencia del náufrago como fruto de su conocimiento adquirido de los patrones económicos de las diferentes tribus indígenas, así como de sus relaciones socio-comerciales (Hickerson 1998: 199-218).

Araucaria. Revista Iberoamericana de Filosofí, Política, Humanidades y Relaciones Internacionales, año $23, \mathrm{n}^{\circ} 47$. Segundo cuatrimestre de 2021. Pp.91-109. ISSN 1575-6823 e-ISSN 2340-2199 https://dx.doi.org/10.12795/araucaria.2021.i47.05 
Álvar Núñez observa en su Relación los usos y costumbres de los diferentes pueblos indígenas en lo referido a la propiedad privada y los intercambios comerciales. Ambos aspectos se convierten en ejes de su actividad intermediadora, y permiten encontrar un código económico común a indios y españoles que ofrece un marco útil para su comunicación y convivencia, y que permite de paso al jerezano ejercer su libertad de desplazarse de un lugar a otro.

Y por esto yo puse en obra de pasarme a los otros, y con ellos me sucedió algo mejor; y porque yo me hice mercader, procuré de usar el oficio lo mejor que supe, y por esto ellos me daban de comer y me hacían buen tratamiento y rogábanme que me fuese de unas partes a otras por cosas que ellos habían menester.

Álvar Núñez Cabeza de Vaca, 1542. Naufragios, capítulo 16.

Estos episodios permiten a Álvar Núñez presentarse ante el emperador como cristiano verdadero, como redentor, como líder valeroso. Ejerce como tal en velado contraste con el papel que los Naufragios reservan a Pánfilo de Narváez y a otros cabecillas de la misión a la Florida. Ante todo, Álvar Núñez quiere dejar constancia de su propio sentido del honor, que no se ve reducido ni por el cautiverio ni por el desempeño de tareas de servidumbre para los indios. Desde el comienzo de su crónica justifica sus propias acciones bajo los parámetros de la honra, sobre todo aquellas en las que incurre en la desobediencia de sus mandos, como cuando se resiste a quedarse en puerto, custodiando los barcos, y prefiere enfrentarse a los peligros de la travesía.

Y que yo quería más aventurarme al peligro que él y los otros se aventuraban, y pasar por lo que él y ellos pasasen, que no encargarme de los navíos, y dar ocasión a que se dijese que, como había contradicho la entrada, me quedaba por temor, y mi honra anduviese en disputa; y que yo quería más aventurar la vida que poner mi honra en esta condición.

Álvar Núñez Cabeza de Vaca, 1542. Naufragios, capítulo 4.

Su texto es entonces una carta de presentación y una hoja de servicios que refleja su ejercicio de unos valores éticos que satisfacen al emperador, conforme al paradigma ideológico y filosófico del nuevo derecho de conquista que el imperio español estaba consolidando. Álvar Núñez Cabeza de Vaca se dirige siempre a su "Sacra, Cesárea, Católica Majestad" con la seguridad de quien se sabe depositario de la verdadera ideología imperial española: su servidumbre es de Dios y del Emperador, no del pecado, la avaricia ni las circunstancias, y en torno a estas premisas, y a las ideas que circulan por la corte española en el momento de la redacción de su Relación, articula su narrativa. ${ }^{31}$ Tanto

31 Véase Sánchez (2018: 682) para un perfil del explorador como buen cristiano. 
su sufrimiento como sus curaciones contribuyen a la plasmación de las líneas maestras de un autorretrato que le proclama como redentor, no solo de los indios sino también de los cristianos. La peculiaridad de su crónica estriba en gran parte en la retórica del fracaso como paso previo a la conquista: su relato no puede vincularse de ningún modo a la tradición épica europea del triunfo militar, pero sí se circunscribe al ethos hispánico del Cid itinerante que lucha por su honra desde la aceptación estoica de la propia vulnerabilidad, "de los sos oios tan fuertemientre llorando", guiado por la fe en unos valores que identifica con los de la monarquía católica española, cuyo amparo solicita. De esta manera, se comprueba cómo el bagaje espiritual e ideológico de Álvar Núñez Cabeza de Vaca no fue fruto exclusivo de su periplo americano, sino más bien de su familiaridad con las coordenadas éticas propias de la España oficial de su tiempo, la que puso los cimientos de una incipiente legalidad internacional.

\section{Bibliografía:}

Adorno, Rolena, "The Negotiation of Fear in Cabeza de Vaca's Naufragios", en Representations, 33 (1991), pp. 163-199.

Adorno, Rolena, The Polemics of Possession in Spanish American Narrative, New Haven, Yale University Press, 2007.

Adorno, Rolena, \& Pautz, Patrick Charles, Álvar Núñez Cabeza De Vaca: His Account, His Life, and the Expedition of Pánfilo De Narváez, Lincoln, University of Nebraska, 1999.

Arellano, Jerónimo, "Reading the Affects in the Colonial Americas: The Exteriority of Feeling in Cabeza De Vaca's Naufragios", en Latin American Research Review, 53.3 (2018), pp. 548-560.

Bauer, Ralph, "Laying Claim to the Literary Borderlands: The Contested Grounds of Hispanism in the US", en American Literary History, 16.3 (2004), pp. 487-495.

Bonvillian, John D., Ingram, Vicky L. \& McCleary, Brendan, "Observations on the Use of Manual Signs and Gestures in the Communicative Interactions between Native Americans and Spanish Explorers of North America", en Sign Language Studies, 9.2 (2009), pp. 132-165.

Borunda, Andrea Phiana, "Performing Cultural Memory in Cabeza De Vaca's La Relación", en Pennsylvania Literary Journal, 8.2 (2016), p. 92.

Defelippe, Florencia, "Narrar la periferia. Constrcciones discursivas y representaciones del espacio en Naufragios y Comentarios, de Álvar Núñez Cabeza de Vaca”, en Exlibris, 6 (2017), pp. 46-53.

Elliott, John, Empires of the Atlantic World: Britain and Spain in America, 1492-1830, New Haven, Yale University Press, 2006.

Elliott, John, History in the Making, New Haven \& London, Yale University Press, 2012.

Fernández de Oviedo, Gonzalo, Historia general y natural de las Indias, IV, Alicante, Biblioteca Virtual Miguel de Cervantes, 2007 [edición original de José Amador de los Ríos, Madrid, Imprenta de la Real Academia de la Historia, 1853]. 
Godoy, Carmen Gloria, “Alteridad y conquista en Naufragios, de Alvar Núñez Cabeza de Vaca”, en Signótica: Revista do Mestrado em Letras e Lingüística, 22.1 (2010), pp. $1-18$.

Gómez-Galisteo, Carmen, Early Visions and Representations of America: Álvar Núñez Cabeza de Vaca's Naufragios and William Bradford's of Plymouth's Plantation, Nueva York, Bloomsbury, 2013.

Goodman, Nan, "Mercantilism and Cultural Difference in Cabeza De Vaca's Relación", en Early American Literature, 40.2 (2005), pp. 229-250.

Goodwin, Robert TC, "'Yo quisiera esto más claro, e más larga claridad en ello'. Reconstruction: Historiographical Misrepresentations of Africans and Native Americans, and the Law", en Bulletin of Spanish Studies, 92.2 (2002), pp. 179-206.

Goodwin, Robert TC, “'De lo que sucedió a los demás que entraron en las Indias': Álvar Núñez Cabeza De Vaca and the Other Survivors of Pánfilo Narváez's Expedition”, en Bulletin of Spanish Studies, LXXXIV.2 (2007), pp. 147-173.

Goodwin, Robert TC, "Álvar Núñez Cabeza de Vaca and the Textual Travels of an American Miracle", en Journal of Iberian and Latin-American Studies, 14.1 (2008), pp. 1-12.

Hachim, Luis, \& Hurtado, Pablo. "El discurso factual y ficcional en la narrativa colonial hispanoamericana: Naufragios [1542] de Álvar Núñez Cabeza de Vaca e Infortunios de Alonso Ramirez [1690] de Carlos de Sigüenza y Góngora”, en Catedral Tomada: Revista de Crítica Literaria latinoamericana, 6.10 (2018), pp. 172-188.

Hickerson, Nancy P., "How Cabeza de Vaca Lived with, Worked among, and Finally Left the Indians of Texas", en Journal of Anthropological Research, 54.2 (1998), pp. 199218.

Howard, David A., Conquistador in Chains: Cabeza de Vaca and the Indians of the Americas, Tuscaloosa, University of Alabama Press, 1996.

Jáuregui, Carlos A., "Cabeza de Vaca, Mala Cosa y las vicisitudes de la extrañeza: para Maureen Ahern (1936-2012), In Memoriam”, en Revista de Estudios Hispánicos, 48.3 (2014), pp. 421-447.

Jiménez Núñez, Alfredo, "Cuando la realidad supera a la ficción. Los Naufragios de Álvar Núñez Cabeza de Vaca”, en Revista de dialectología y tradiciones populares, 60.1 (2005), pp. 109-121.

Jong Lee, Kun, "Pauline Typology in Cabeza De Vaca's Naufragios", en Early American Literature, 34.3 (1999), pp. 241-262.

Krieger, Alex D., We Came Naked and Barefoot: The Journey of Cabeza de Vaca across North America, Austin, University of Texas Press, 2002.

Liparulo, Steven P., "From Fear to Wisdom: Augustinian Semiotics and Self-Fashioning in Cabeza De Vaca's Relación", The Arizona Quarterly, 62.2 (2006), pp. 1-25.

Marešová, Jaroslava, "Los náufragos del XVI: la experiencia en el mundo del Otro", en Svět Literatury, 26 (2016), pp. 33-41.

Morell, Elvira Aballí, "La aporía de los Naufragios", en The Latin Americanist, 62.3 (2018), pp. 399-413.

Núñez Cabeza de Vaca, Álvar, Naufragios, Alicante, Biblioteca Virtual Miguel de Cervantes, 2003 [edición original 1542].

Payne, Stanley, Spain: A Unique History, Madison, University of Wisconsin, 2011. 
Pupo-Walker, Enrique, "Notas para la caracterización de un texto seminal: los Naufragios de Álvar Núñez Cabeza de Vaca”, en Nueva Revista de Filología Hispánica, 38.1 (1990), pp. 163-196.

Rabasa, José, "De la allegoresis etnográfica en los Naufragios de Álvar Núñez Cabeza de Vaca", en Revista Iberoamericana, 61.170 (1995), pp. 175-185.

Rabin, Lisa, "Figures of Conversion and Subjectivity in Colonial Narrative", en Hispania, 82 (1999), pp. 40-45.

Roca Barea, María Elvira, Imperiofobia y leyenda negra: Roma, Rusia, Estados Unidos y el Imperio español, Madrid, Siruela, 2016.

Sánchez, Ramón, "La lucha de Álvar Núñez Cabeza de Vaca por un discurso validador que confirme su estatus de 'cristiano verdadero' como esclavo/cautivo en la Relación (1542)", en Revista de Indias, 78.274 (2018), p. 659.

Schneider, Paul, Brutal Journey, Cabeza de Vaca and the Epic First Crossing of North America, Nueva York, Henry Holt, 2007.

Smith, Cassander, "Beyond the Mediation: Esteban, Cabeza de Vaca's Relación, and a Narrative Negotiation", en Early American Literature, 47.2 (2012), pp. 267-291.

Todorov, Tzvetan, La conquista de América: el problema del otro, México DF y Buenos Aires, Siglo XXI, 1982.

Udall, Stewart L., Majestic Journey: Coronado's Inland Empire, Santa Fe, Museum of New Mexico Press, 1995.

Vargas, Claret M., "De muchas y muy bárbaras naciones con quien conversé y viví: Álvar Núñez Cabeza de Vaca's Naufragios as a War Tactics Manual”, en Hispanic Review, 75.1 (2007), pp. 1-22.

Varnum, Robin, Álvar Núñez Cabeza de Vaca: American Trailblazer, Norman, OK: University of Oklahoma Press, 2014.

Villaverde Rico, María José \& Castilla Urbano, Francisco, eds., La sombra de la leyenda negra, Madrid, Tecnos, 2016.

de Vitoria, Francisco, Relecciones sobre los indios y el derecho de guerra, Madrid, Espasa Calpe, 1975, [edición original 1538].

Whatley, Janet, "Introduction" [en Jean de Léry, History of a Voyage to the Land of Brazil, Otherwise Called America, Berkeley, University of California Press, 1990], pp. xvlxii.

Wild, Peter, Álvar Núñez Cabeza de Vaca, Boise, ID, Boise State University, 1991.

Zaidi, Ali Shehzad, "The Spiritual Evolution of Cabeza De Vaca in Shipwrecks", en Theory in Action, 7.3 (2014), pp. 109-17. 
